\title{
O discurso do rei: tradução e poder
}

\author{
Terezinha Rivera Trifanovas ${ }^{*}$
}

\begin{abstract}
The movie The King's Speech is the object of this study aimed to observe the communicative interactions between the leading characters (the British King George, the VI, and the Australian therapist Lionel Logue) in order to analyze effects of meaning identified around the power relationship in the original screenplay in English as well as in the subtitled translation in Portuguese. To accomplish this objective, the most representative dialogues concerning power relationship were selected and the linguistic materiality was analyzed from a discursive perspective based on the relations of language, subject and history which considers the conditions of production and the effects of meaning. It is important to emphasize that the objective of this article is not to analyze the translation quality but to observe how the effects of meaning are constructed regarding the power relationship from English to Portuguese language.
\end{abstract}

Keywords: discourse; translation; power and knowledge relationship.

Resumo: Tomando como objeto de estudo o filme intitulado 0 discurso do rei, observou-se, particularmente, as interações comunicativas entre os protagonistas (o rei britânico George VI e o terapeuta australiano Lionel Logue), com o intuito de analisar os efeitos de sentido identificados, pelos autores do artigo, em torno das relações de poder presentes no discurso original em língua inglesa e na tradução legendada para a língua portuguesa. Para isso, foram selecionados os diálogos mais representativos das relações de poder entre as referidas personagens e empreendida a análise da materialidade linguística por uma perspectiva discursiva, centrada no estudo das relações entre linguagem, sujeito e história, que considera as condições de produção e os efeitos de sentido. Ressalta-se, porém, não ser a intenção analisar a qualidade da atividade tradutória, mas, sim, observar como se dá a construção de efeitos de sentido relacionados às relações de poder de um idioma para outro.

Palavras-chave: discurso; tradução; relações de poder-saber.

\footnotetext{
* Professora do Centro de Linguagem e Comunicação (CLC), Faculdade de Letras, da Pontifícia Universidade Católica de Campinas (PUC - Campinas). Email: trifanovas@ig.com.br.
} 


\section{Considerações iniciais}

Este estudo foi concebido a partir do filme intitulado 0 discurso do rei ${ }^{1}$ que, baseado na história real do rei George VI, retrata os problemas do monarca em expressar-se publicamente. Após a morte de seu pai, o rei George V, e a abdicação escandalosa de seu irmão, o rei Eduardo VIII (príncipe de Gales), Albert George (duque de York), vítima de um problema de fala por toda a sua vida, de repente é coroado rei George VI da Inglaterra. Com a iminência da guerra e o país necessitando desesperadamente de um líder, sua esposa, Elizabeth (duquesa de York), a futura rainha mãe, envia o marido a uma consulta com um excêntrico terapeuta da fala, Lionel Logue, um fracassado ator australiano.

Após um começo difícil, os dois embarcam em um tratamento pouco ortodoxo e, eventualmente, formam um vínculo inquebrável. Com o apoio de Logue, de sua família, de seu governo e de Winston Churchill, o rei vai superar sua gagueira e proferir o seu mais importante discurso no rádio às vésperas da Segunda Guerra Mundial. A partir desse enredo, apresenta-se, a seguir, o estudo de caso das trocas comunicativas produzidas entre o rei George VI, o terapeuta da fala Lionel Logue e a Duquesa Elizabeth, observando, particularmente, se as relações de poder-saber são evidenciadas na tradução desses diálogos.

Partindo do pressuposto que figuras soberanas e membros de famílias reais produzem, no imaginário coletivo, imagens de poder, de autoridade, de força e de segurança, apresenta-se a hipótese de que 0 ato tradutório está permeado por esse imaginário coletivo, refletindo sobremaneira na atividade do suj eito tradutor. Em consonância com esta hipótese, o objetivo geral deste

\footnotetext{
${ }^{1}$ The king's speech. Produção de lain Canning, Emile Sherman, Gareth Unwin. Roteiro de David Seidler. Direção de Tom Hooper. Protagonistas: Colin Firth, Geoffrey Rush, Helena Bonham Carter e Guy Pearce. The Weinstein Company e UK Film Council. Paris Filmes. 2010. Lançamento, nos EUA, em 24/ 12/ 2010 e, no Brasil, em 11/2/ 2011.
} 
Trifanovas, T. R. - 0 discurso do rei: tradução e poder

artigo foi o de problematizar as relações de poder/saber observadas na legendagem ${ }^{2}$ das interações comunicativas dos protagonistas do filme.

Apoiaremo-nos nas contribuições teóricas de Foucault, que afirma que as relações de poder estão disseminadas por todo o tecido social (Foucault 1976[1984: 89]) $)^{3}$, e de Pechêux, que, relativizando a noção de interpretação, problematiza a suposta transparência e evidência do sentido. Ademais, a análise da materialidade linguística, ou seja, do intradiscurso, do fio do dizer, propicia a identificação dos sentidos contidos nos enunciados, não pelo desejo de encontrar sentidos ocultos, mas, ao contrário, para evidenciar possibilidades de sentido delineadas pelas condições de produção, com seus desdobramentos na constituição das subj etividades.

Uma das grandes contribuições trazidas por Foucault diz respeito à proposta de não se esgotar a possibilidade de detectar e analisar como e onde as relações de poder são legitimadas. Não se trata apenas de dizer se há ou não poder em uma dada circunstância, nem mesmo de dizer quem detém 0 poder, mas de, constantemente, identificar e descrever como relações de poder são configuradas e quais as suas consequências na constituição dos sujeitos. Para Foucault, o poder está presente no cotidiano familiar, profissional, acadêmico ou político-social, como ele próprio afirma:

Onipresença do poder: não porque tenha o privilégio de agrupar tudo sob sua invencível unidade, mas porque se produz a cada instante, em todos os pontos, ou melhor, em toda relação entre um ponto e outro. 0 poder está em toda parte; não porque englobe tudo e sim porque provém de todos os lugares (FOUCAULT 1976[1984: 89]).

Dos diálogos entre o Duque Albert, o terapeuta Lionel e a Duquesa Elizabeth foram selecionados recortes discursivos que constituíram o corpus de pesquisa, para efetuar a análise da materialidade linguística e das

\footnotetext{
${ }^{2} 0$ corpus de pesquisa é advindo da legendagem produzida pela Equipe Victorians (tradução, revisão e sincronia), disponibilizada em 25/4/2011. O lançamento nacional do filme, em DVD, ocorreu em 22/ 06/ 2011.

${ }^{3} \mathrm{~A}$ primeira data refere-se à publicação original e a segunda refere-se à tradução consultada.
} 
Trifanovas, T. R. - 0 discurso do rei: tradução e poder

condições de produção, as quais, quando agrupadas, constroem efeitos de sentido e, assim, foram observadas as configurações de relações de poder/ saber pelo viés do discurso.

No que diz respeito à análise da materialidade linguística, foram focalizadas as estratégias argumentativas de natureza verbal. Abordou-se, por exemplo, a modalização no discurso dos protagonistas do referido filme, a fim de analisar as ocorrências enunciativas que legitimam as relações de poder de um sobre o outro.

No que tange à perspectiva discursiva a partir das condições de produção, CORACINI (1991: 339) aponta que há duas possibilidades de abordagens metodológicas: 1) análise de texto ou linguística textual, que parte do texto para recuperar vestígios extralinguísticos da situação de enunciação; 2) análise de discurso que parte de uma representação das condições de produção do discurso (que nunca podem ser realmente restabelecidas), sem excluir a situação de enunciação. Neste estudo decidiuse pela segunda orientação metodológica, a discursiva, a fim de compreender a complexidade das condições de produção que possibilitam a realização linguística. Coracini (1991) sugere que:

[...] a metodologia de Análise de Discurso que privilegia as condições de produção como norteadoras de sua análise, na medida em que não fecha a questão, pré-determinando (sic) formas linguísticas capazes de veicular subjetividade ou objetividade, denotação ou conotação, está mais apta a assimilar uma visão pós-modernista de ciência que apesar de reconhecer "o peso das instituições que impõe limites aos jogos de linguagem e assim restringem a inventividade dos parceiros em matéria de lance" (LYOTARD 1988: 31), entende que é possível romper com as regras pré-estabelecidas (sic) "se os limites da antiga instituição forem ultrapassados (op. cit. 32)" (CORACINI 1991: 351).

Objetivando delinear mais amiúde a perspectiva discursiva adotada nestas análises, apresenta-se, a seguir, uma breve compilação acerca de algumas noções fundadoras concebidas pelos estudos do discurso e pelos estudos da tradução em uma perspectiva desconstrutivista. Alguns conceitos 
Trifanovas, T. R. - 0 discurso do rei: tradução e poder

norteadores da Análise de Discurso dizem respeito à análise da configuração discursiva, introduzindo noções de polissemia e de efeitos de sentido. Etimologicamente, a palavra discurso tem em si a ideia de curso, de percurso, de correr para diversas partes, de pôr em movimento, de tomar várias direções. "O discurso é assim palavra em movimento, prática de linguagem. Com o estudo do discurso observa-se o homem falando" (ORLANDI 2001: 15). Entende-se, pois, o discurso a partir do funcionamento dos efeitos de sentido entre locutores e outros discursos (interdiscurso) e da configuração das condições de produção; todos esses elementos contribuem para se pensar a equivocidade e a opacidade constitutiva da linguagem.

Diante do fato do discurso ser interpenetrado por outros discursos é que se pode considerar a heterogeneidade discursiva constitutiva (AUtHIER-Revuz 1998), ou interdiscurso, como inerentemente dialógica. A heterogeneidade discursiva consiste de fragmentos de múltiplos discursos com aparições esporádicas em determinados pontos de emergência; é também a manifestação da memória discursiva, ou seja, inúmeras vozes anteriores e exteriores entrelaçadas em uma rede de sentidos, quase apagando suas origens. Se o interdiscurso é esse entrelaçamento de discursos disseminados que aparecem explícita ou implicitamente na superfície discursiva heterogeneidade discursiva mostrada (AUTHIER-REVUz 1998) -, o intradiscurso é a materialidade linguística, é o fio discursivo que se materializa, constituindo o próprio texto.

Nas teorias de discurso, é essencial observar as condições de produção do discurso, isto é, toda a circunstancialidade sociopolítico-histórica ao redor do ato enunciativo. Essa contextualização está consideravelmente atrelada às formações discursivas propostas por FoucAult (1969 [2005: 130]), entendidas como sendo o discurso em formação, sempre em mobilidade, instável, mapeando em um dado momento histórico-social as possibilidades de expressão. CORACINI (2007: 9) afirma que "essa rede conforma e é conformada por valores, crenças, ideologias, culturas que permitem aos sujeitos ver 0 
mundo de uma determinada maneira e não de outra, que Ihes permitem ser, ao mesmo tempo, semelhantes e diferentes."

\section{Contextualização do enredo}

Em O Discurso do Rei, as amarguras emocionais do futuro rei George VI (Albert George, duque de York) ganham destaque, em toda a Inglaterra, a partir de sua dificuldade de se expressar, principalmente em pronunciamentos públicos, devido à sua gagueira. Solidária ao marido, e após tentativas fracassadas com vários médicos renomados, a duquesa de York (futura rainhamãe do trono britânico) busca a ajuda do terapeuta da fala Lionel Logue, detentor de um método inusitado nas primeiras décadas do século XX. 0 método de Lionel advém de sua fracassada carreira teatral, de sua paixão pelo teatro de Shakespeare e de sua experiência tratando soldados traumatizados, após o fim da primeira guerra mundial. Lionel desenvolverá uma relação de amizade com Albert George, segundo nome na lista de sucessão ao trono britânico.

Durante as sessões em que são trabalhados o relaxamento muscular e o controle respiratório, a gagueira do príncipe Albert traz muito mais do que uma mera dificuldade de fala. Há todo o lado psicológico, e até mesmo social, por trás dela, desde o modo de criação na infância, considerado corriqueiro para a educação formal entre os nobres da época - a severidade do pai, a repressão por ser canhoto, o doloroso tratamento de seu joelho, a crueldade de uma babá que preferia seu irmão mais velho e a morte de seu irmão mais novo, príncipe J ohn -, até o peso carregado pela posição que ocupa. Ademais, George conhece bem os deveres e o ônus do ofício de ser rei e não se considera apto para a função em virtude de sua gagueira. 
Trifanovas, T. R. - 0 discurso do rei: tradução e poder

Muito mais do que propor exercícios vocais, Lionel atua como psicólogo do monarca, mesmo enfrentando uma pesada barreira de desconfiança e de diferença de classes. Embora Albert George seja complacente para com 0 cidadão comum, ele reforça a diferença social e hierárquica entre nobres e plebeus. Prova disso é a atitude elitista de Albert em resistir à proposta de Lionel de ambos se tratarem como iguais. Lionel, por sua vez, insistia em chamar o monarca pelo apelido de Bertie, de uso exclusivo dos familiares e amigos íntimos. Assim, há o contraste entre o temperamento explosivo do membro da realeza e a ousadia de um homem comum, bem como a cumplicidade que alicerça uma amizade construída pela distância e, ao mesmo tempo, pela aproximação, ou seja, o paradoxo de dois homens: um falante competente da língua que não obteve sucesso profissional (o ator fracassado) e um falante deficitário da língua que possuía tudo para obter sucesso histórico (o monarca em fracasso).

Articulando tal discussão ao objetivo geral do artigo de problematizar as relações de poder/saber produzidas durante as interações comunicativas entre os protagonistas do filme, decidiu-se, inicialmente, apresentar a transcrição completa de uma cena do filme (corpus de pesquisa) e, em seguida, selecionar algumas falas e contrastá-las com a tradução legendada, produzindo, assim, recortes discursivos (RD) para análise da materialidade linguística. Com isso, foi possível alcançar os objetivos específicos pretendidos, quais eram: a) discutir a escolha lexical da tradução em português do Brasil; b) observar a legitimação de poder por meio da tradução; c) refletir sobre a construção, em uma perspectiva discursiva, de efeitos de sentido presentes na tradução.

\section{Dispositivo analítico}

A cena, a seguir, retrata o momento em que a Duquesa de York vai ao consultório do terapeuta da fala, Sr. Lionel Logue, a fim de conhecê-lo e, 
Trifanovas, T. R. - 0 discurso do rei: tradução e poder

possivelmente, convencer o marido, Duque de York, a iniciar um tratamento para a gagueira dele. De antemão, ambos tentam estabelecer as bases para 0 relacionamento interpessoal. Ela, lentamente, revelando sua superior posição social e, ele, rapidamente, demandando igualdade de tratamento. A assimetria das posições desses suj eitos ocasiona atrito e ruído nas relações de poder.

\section{DIÁLOGO 1: Vídeo (tempo 0:09:04 - 0:12:16)}

Roteiro (páginas 7 - 10)

\begin{tabular}{|c|c|}
\hline ELIZABETH & Hello. Is anyone there? \\
\hline LIONEL & I'm just in the loo. \\
\hline LIONEL & "Poor and content is rich and rich enough" \\
\hline ELIZABETH & I beg your pardon? \\
\hline LIONEL & $\begin{array}{l}\text { Shakespeare. I'm sorry, there's no receptionist. I like to } \\
\text { keep things simple. How are you Mrs. J ohnson? I'm afraid } \\
\text { you're late. }\end{array}$ \\
\hline ELIZABETH & I'm afraid I am. \\
\hline LIONEL & Where's Mr. J ohnson? \\
\hline ELIZABETH & He doesn't know I'm here. \\
\hline LIONEL & That's not a promising start. \\
\hline ELIZABETH & $\begin{array}{l}\text { My husband has seen everyone to no avail. He's given up } \\
\text { hope. }\end{array}$ \\
\hline LIONEL & He hasn't seen me. \\
\hline ELIZABETH & You're awfully sure of yourself. \\
\hline LIONEL & I'm sure of anyone who wants to be cured. \\
\hline \multirow[t]{2}{*}{ ELIZABETH } & Naturally he wishes to be cured. \\
\hline & My husband is required to speak publicly. \\
\hline LIONEL & Perhaps he should change jobs. \\
\hline ELIZABETH & He can't. \\
\hline LIONEL & Indentured servitude? \\
\hline ELIZABETH & Something of that nature. \\
\hline LIONEL & $\begin{array}{l}\text { Well have your hubby pop by...Tuesday would be } \\
\text { good...to give his personal history and I'll make a frank } \\
\text { appraisal. }\end{array}$ \\
\hline ELIZABETH & $\begin{array}{l}\text { I do not have a "hubby". We don't 'pop'. We never talk } \\
\text { about our private lives. You must come to us. }\end{array}$ \\
\hline LIONEL & Sorry, Mrs. J ohnson, my game, my turf, my rules. \\
\hline ELIZABETH & And what if my husband were the Duke of York? \\
\hline
\end{tabular}


Trifanovas, T. R. - 0 discurso do rei: tradução e poder

\begin{tabular}{|c|c|}
\hline LIONEL & The Duke of York? \\
\hline ELIZABETH & Yes the Duke of York. \\
\hline LIONEL & $\begin{array}{l}\text { I thought the appointment was for "J ohnson"? Forgive } \\
\text { me, your Royal...? }\end{array}$ \\
\hline ELIZABETH & Highness. \\
\hline LIONEL & Your Royal Highness. \\
\hline ELIZABETH & $\begin{array}{l}\text { J ohnson was used during the Great War when the Navy } \\
\text { didn't want the enemy to know 'he' was aboard. We are } \\
\text { operating under the strictest of confidences. }\end{array}$ \\
\hline LIONEL & Of course. I'm considered the enemy? \\
\hline ELIZABETH & You will be if you remain unobliging. \\
\hline LIONEL & How did you find me? \\
\hline ELIZABETH & The President of the Speech Therapists Society. \\
\hline LIONEL & Eileen McCleod? She's a sport. \\
\hline ELIZABETH & $\begin{array}{l}\text { Dr. McCleod warned me your antipodean methods } \\
\text { were "unorthodox and controversial". I warned } \\
\text { her...they were not my favorite words. }\end{array}$ \\
\hline LIONEL & I succeed. \\
\hline ELIZABETH & So she says. \\
\hline LIONEL & $\begin{array}{l}\text { I can cure your husband. But for my method to work } \\
\text { there must be trust and total equality in the safety of } \\
\text { my consultation room. No exceptions. }\end{array}$ \\
\hline ELIZABETH & Well then, in that case... \\
\hline ELIZABETH & When can you start? \\
\hline
\end{tabular}

Vejamos, a seguir, como as falas selecionadas em negrito foram traduzidas, a fim de observarmos a produção de efeitos de sentido.

\author{
RD 1 \\ ELIZABETH My husband is required to speak publicly \\ Meu esposo é... Ele precisa falar em público. \\ LIONEL Indenturedservitude \\ Contrato a prazo fixo?
}

Primeiramente, observamos a utilização de reticências e a repetição do sujeito oracional (Meu esposo é... Ele), que aponta para a possibilidade de 0 tradutor ter a intenção de marcar o trabalho de interpretação cênica do ator, considerando que tal repetição não consta do roteiro. Em seguida, a escolha pelo verbo "precisar", no presente simples, em lugar da voz passiva da 
Trifanovas, T. R. - 0 discurso do rei: tradução e poder

locução verbal em inglês (is required), aponta para uma modalização do discurso, considerando que as possibilidades em português - ser exigido, ser demandado, ser obrigado -, poderiam soar negativamente na tradução da fala de uma personagem de origem nobre. Neste sentido, o tradutor encontra maior desafio com o vocábulo indentured, pois, na tentativa de manter a modalização do discurso da personagem nobre, optou por "contrato a prazo fixo", quebrando, assim, o paradoxo do vocábulo que denota serviço quase escravo.

A partir dessa escolha vocabular, emerge efeitos de sentido de que, durante 0 ato tradutório, há a preocupação com uma propriedade lexical em detrimento do paradoxo possivelmente desejado pelo roteirista. Ou seja, um diálogo velado entre personagens: uma duquesa da família real britânica que, ao tentar dissimular sua identidade e a do esposo, se vê presa em um jogo de perguntas nada familiar e, de outro lado, um plebeu se apossando de frestas discursivas, detectadas por seu raciocínio rápido e viabilizadas por sua destreza lexical.

\section{RD 2}

ELIZABETH You will be if you remain unobliging. Será, se prevalecer a imprudência.

Enfatizando que neste estudo não se objetivou verificar a qualidade da tradução, mas, sim, refletir sobre a possibilidade de relações de poder advindas da temática do filme - o poder do soberano e a autoridade médica -, influenciar 0 ato tradutório. Assim, não parece adequado pensar que, em RD 2, a tradução para os verbos remain e unoblige seja resultado de descuido ou inexperiência. Pensamos que a escolha (prevalecer a imprudência) remete ao próprio momento da enunciação, que parece revelar o lugar instável do suj eito tradutor capturado na trama do enredo, considerando que remain unobliging aponta para uma possível ameaça da interlocutora, dirigida ao seu interlocutor, levando-se em consideração que a escolha tradutória por 
Trifanovas, T. R. - 0 discurso do rei: tradução e poder

"imprudência" se mostra mais categórica do que a possibilidade tradutória por "continuar desobrigado". Com isso, o suj eito tradutor tenta assegurar a autoridade da personagem nobre sobre a do plebeu, ao demandar respeito aos desígnios de um soberano.

\title{
RD 3
}

ELIZABETH Dr. McCleod warned me your antipodean methods were "unorthodox and controversial".

Ela me advertiu que seus métodos eram "heterodoxos e controversos".

A priori, há pouca dificuldade em encontrar tradução para a palavra antipodean (antípoda), contudo, a omissão deste vocábulo produz o efeito de que a inclusão de mais uma palavra requintada (em conjunto com heterodoxo e controverso) seria, talvez, para o sujeito tradutor, um excesso desnecessário para definir os métodos do terapeuta plebeu. Tal possibilidade reforça a análise apresentada, em RD 2, acerca do lugar instável do tradutor que se reverencia diante da personagem nobre, por meio de sua escolha lexical, ou seja, o tradutor faz escolhas lexicais a partir da posição social da personagem, subvertendo o roteiro em subserviência à personagem soberana.

Dando prosseguimento, a próxima cena se desenrola em torno do primeiro encontro entre o terapeuta e o príncipe, que fora persuadido por sua esposa a ir ao consultório do inusitado especialista. Vemos, neste encontro, a exposição das personalidades de ambos: um príncipe ansioso, impaciente e inseguro e um terapeuta firme, paciente e seguro.

\author{
DIÁLOGO 2 Vídeo (tempo 20:23 - 28:48) Roteiro (páginas \\ 19 - 25) \\ LIONEL I was told not to sit too close. \\ LIONEL I was also told, speaking with a Royal, one waits for the \\ Royal to choose the topic.
}


Trifanovas, T. R. - O discurso do rei: tradução e poder

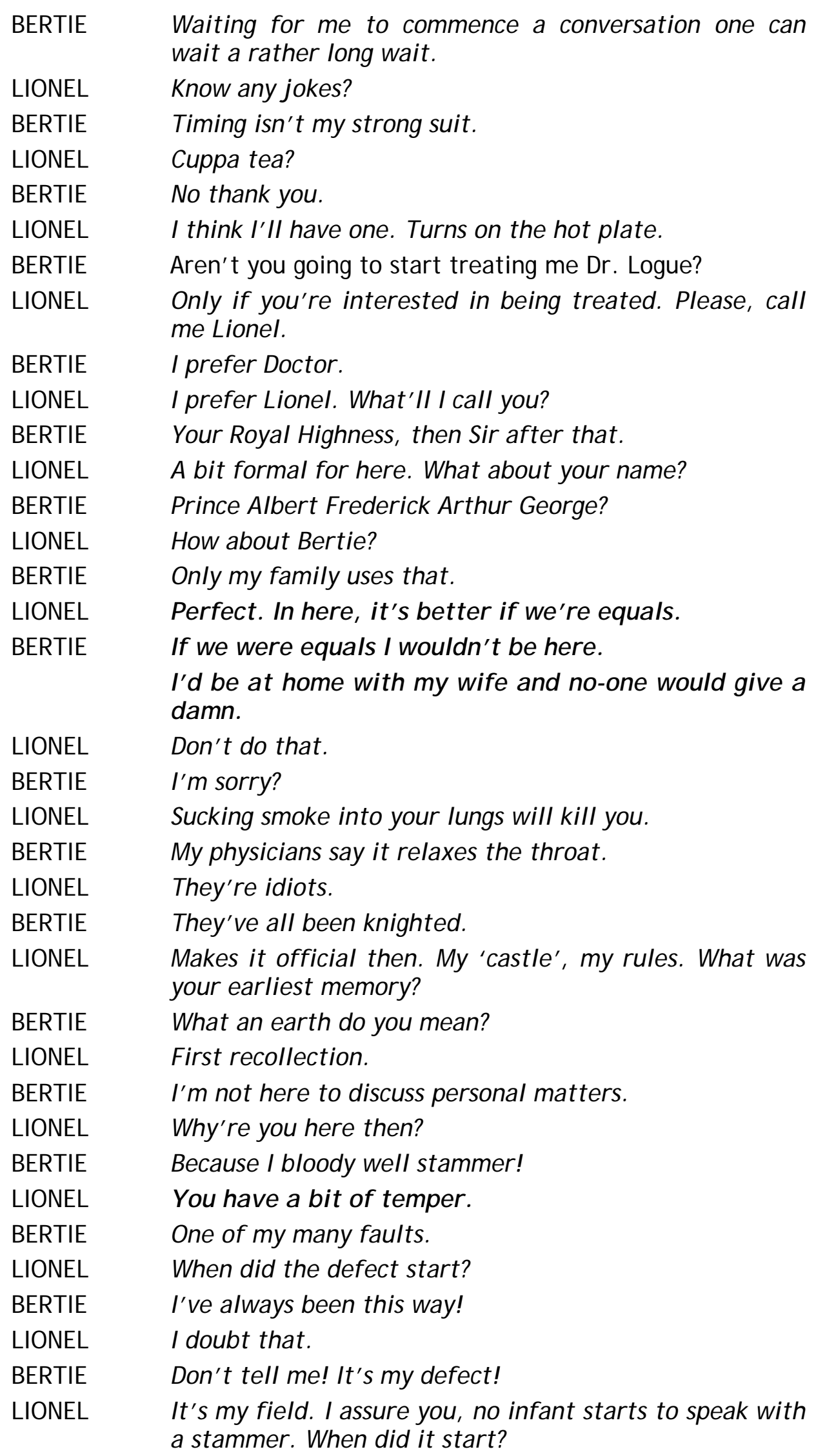


Trifanovas, T. R. - 0 discurso do rei: tradução e poder

\begin{tabular}{|c|c|}
\hline BERTIE & Four or five. \\
\hline LIONEL & That's typical. \\
\hline BERTIE & So I've been told. I can't remember not doing it. \\
\hline LIONEL & That I believe. Do you hesitate when you think? \\
\hline BERTIE & Don't be ridiculous. \\
\hline \multirow[t]{2}{*}{ LIONEL } & $\begin{array}{l}\text { One of my many faults. How about when you talk to } \\
\text { yourself? }\end{array}$ \\
\hline & Everyone natters occasionally, Bertie. \\
\hline BERTIE & Stop calling me that! \\
\hline LIONEL & I'm not going to call you anything else. \\
\hline BERTIE & Then we shan't speak! \\
\hline BERTIE & Are you charging for this, Doctor? \\
\hline LIONEL & $\begin{array}{l}\text { A fortune. So, Bertie... when you talk to yourself, do } \\
\text { you stammer? }\end{array}$ \\
\hline BERTIE & Of course not! \\
\hline \multirow[t]{2}{*}{ LIONEL } & $\begin{array}{l}\text { Thus proving your impediment isn't a permanent part of } \\
\text { you. }\end{array}$ \\
\hline & What do you think was the cause? \\
\hline BERTIE & $\begin{array}{l}\text { I don't know! I don't care! I stammer. And no one can } \\
\text { fix it. }\end{array}$ \\
\hline LIONEL & $\begin{array}{l}\text { Bet you, Bertie, you can read flawlessly, right here, } \\
\text { right now. }\end{array}$ \\
\hline LIONEL & And if I win, I get to ask questions. \\
\hline BERTIE & And if I win? \\
\hline LIONEL & You don't have to answer. \\
\hline BERTIE & One usually wagers money. \\
\hline LIONEL & A bob each to sweeten it? See your shilling. \\
\hline BERTIE & I don't carry cash. \\
\hline LIONEL & I had a funny feeling you mightn't. \\
\hline LIONEL & Stake you. Pay me back next time. \\
\hline BERTIE & If there is a next time. \\
\hline LIONEL & I haven't agreed to take you on. \\
\hline BERTIE & I can't possibly read this. \\
\hline LIONEL & Then you owe me a shilling for not trying. \\
\hline BERTIE & $\begin{array}{l}\text { "To be or not to be, That is the question. Whether it is } \\
\text { wiser..." There! }\end{array}$ \\
\hline BERTIE & I can't read! \\
\hline LIONEL & I haven't finished yet. \\
\hline \multirow[t]{2}{*}{ LIONEL } & $\begin{array}{l}\text { I'm going to record your voice and then play it back to } \\
\text { you on the same machine. }\end{array}$ \\
\hline & $\begin{array}{l}\text { This is brilliant. It's the latest thing from America: a } \\
\text { Silvertone. }\end{array}$ \\
\hline
\end{tabular}


Trifanovas, T. R. - 0 discurso do rei: tradução e poder

$\begin{array}{ll}\text { LIONEL } & \text { There's a bob in this, mate. You can go home rich! } \\ \text { BERTIE } & \text { You're playing music. } \\ \text { LIONEL } & \text { I know. } \\ \text { BERTIE } & \text { How can I hear what I'm saying?! } \\ \text { LIONEL } & \text { Surely a Prince's brain knows what its mouth is doing? } \\ \text { BERTIE } & \text { You're not well acquainted with Royal Princes, are you? } \\ \text { BERTIE } & \text { Hopeless. Hopel ess! } \\ \text { LIONEL } & \text { You were sublime. Would I lie to a prince of the realm } \\ & \text { to win twelve pence? } \\ \text { BERTIE } & \text { I've no idea what an Australian might do for that sort of } \\ & \text { money. } \\ \text { LIONEL } & \text { Shall I play it? } \\ \text { BERTIE } & \text { No. } \\ \text { LIONEL } & \text { If you prefer, we'Il just get on to the questions. } \\ \text { BERTIE } & \text { Thank you Doctor, I don't feel this is for me. } \\ \text { LIONEL } & \text { Sir? The recording is free. Please keep it as a souvenir? }\end{array}$

Vejamos, a seguir, como as falas selecionadas em negrito foram traduzidas, a fim de observarmos a produção de efeitos de sentido.

\author{
RD 4 \\ LIONEL Perfect. In here, it's better if we were equals. \\ Perfeito. Aqui, é melhor se estivermos entre iguais. \\ BERTIE If we were equals I wouldn't be here. \\ Se fôssemos iguais, eu não estaria aqui.
}

Neste RD4, a tradução da expressão IF we were equals mostra a falta de paralelismo verbal para o mesmo enunciado, com a utilização do verbo estar (estivermos) e do verbo ser (fôssemos). No caso da conjugação "estivermos", na primeira pessoa do plural no futuro simples do subjuntivo (que expressa um fato que poderá acontecer no futuro em relação ao momento atual; uma possibilidade ou um desejo) faz emergir a possível preocupação do suj eito tradutor em tratar a fala do terapeuta como incerteza presente, em uma tentativa de apagar a arrogância da personagem, ou mesmo de retirar o que ele demanda durante todo o enredo, ou seja, igualdade. Isso, 
talvez, encontre justificativa na noção construída no imaginário coletivo de que um soberano não recebe exigências de um homem comum.

Já a conjugação "fôssemos", na primeira pessoa do plural no pretérito imperfeito do subjuntivo (que indica uma condição contrafatual, ou seja, que não se verifica na realidade, que teria certa consequência, podendo se referir ao passado, ao presente ou ao futuro) revela que a fala da personagem do duque é tratada como hipotética, ou mesmo irreal, ou seja, eles nunca seriam ou serão iguais. Assim, o sujeito tradutor faz emergir o desejo de fortalecer ou asseverar a posição do nobre que tem sua posição de soberano desafiada, ou mesmo desacreditada, por um plebeu. Diante isso, o sujeito, na posição de tradutor, constitui-se pela linguagem como sujeito pós-moderno, clivado e cindido, durante a tarefa de tradução.

\section{RD 5}

BERTIE l'd be at home with my wife and no-one would give a damn.

Eu estaria em casa com minha esposa e ninguém se importaria.

Quanto à escolha tradutória da expressão give a damn traduzida por "importaria", reforça o raciocínio exposto em RD 4. Se um homem comum não pode demandar nada de um nobre, tampouco é apropriado que um príncipe, cujo pai é o representante maior da igreja anglicana, use uma expressão que remete a uma blasfêmia religiosa (maldição, danação). Em uma palavra, o sujeito, na função de tradutor, exclui um plebeu do jogo simétrico de relações de poder e impede que uma palavra mundana seja proferida por um nobre.

\section{RD 6}

LIONEL You have a bit of temper.

Você é nervoso? 
Trifanovas, T. R. - 0 discurso do rei: tradução e poder

Acentuando, ainda mais, a resistência do tradutor aos artifícios da personagem eloquente do terapeuta, vemos a afirmação you have a bit of a temper ser traduzido na forma de uma pergunta "você é nervoso?", reforçando as duas análises anteriores de que o especialista deve ser submisso diante de um príncipe, fazendo perguntas pertinentes à área médica e não lançando afirmações desconcertantes sobre a personalidade do monarca.

No próximo diálogo, uma sessão iniciada no consultório e terminada em um parque, o príncipe George relata a Lionel Logue uma discussão que teve com seu irmão David, recém-coroado Rei Eduardo VIII, lamentando sua incapacidade de revidar verbalmente às provocações do irmão. 0 príncipe discorre também sobre a situação amorosa do Rei que planeja casar-se com a americana Wallis Simpson (futura Duquesa de Windsor), à época duplamente divorciada, o que comprometeria sua permanência no trono e, possivelmente, resultaria na coroação do príncipe George, sucessor direto ao trono britânico. 
Trifanovas, T. R. - 0 discurso do rei: tradução e poder

\begin{tabular}{|c|c|}
\hline LIONEL & Is that serious? \\
\hline & Your place might well be on the throne. \\
\hline BERTIE & I am not an alternative to my brother. \\
\hline LIONEL & You can outshine David... \\
\hline BERTIE & Don't take liberties! That's bordering on treason. \\
\hline LIONEL & I'm just saying you could be King. You could do it! \\
\hline BERTIE & That is treason! \\
\hline LIONEL & $\begin{array}{l}\text { I'm trying to get you to realize you need not be } \\
\text { governed by fear. }\end{array}$ \\
\hline BERTIE & I've had enough of this! \\
\hline LIONEL & What're you afraid of? \\
\hline BERTIE & Your poisonous words! \\
\hline LIONEL & $\begin{array}{l}\text { Why'd you show up then? } \\
\text { To take polite elocution lessons so you can chit-chat at } \\
\text { posh tea parties? }\end{array}$ \\
\hline BERTIE & $\begin{array}{l}\text { Don't instruct me on my duties! I'm the brother of a } \\
\text { King...the son of a King... } \\
\text { we have a history that goes back untold centuries. } \\
\text { You're the disappointing son of a Brewer! } \\
\text { A jumped-up jackeroo from the outback! You're nobody. } \\
\text { These sessions are over! }\end{array}$ \\
\hline
\end{tabular}

Vejamos, a seguir, como as falas selecionadas em negrito foram traduzidas, a fim de observarmos a produção de efeitos de sentido.

\section{RD 7}

LIONEL Where does that leave you?

E qual é o seu papel em tudo isso?

Observa-se que a escolha que o sujeito tradutor encontrou para traduzir uma sentença relativamente simples (where does that leave you?) aponta para a possibilidade de o tradutor ser fisgado pela trama do enredo que ele interpreta e traduz ao mesmo tempo. 0 tradutor, simultaneamente, se coloca nas posições de leitor ativo que interpreta, de tradutor que escreve e de expectador que legenda as falas. Assim, este sujeito cindido e fragmentado, talvez, perceba na trama um desejo inconsciente da personagem do terapeuta e o materializa ao traduzir Where does that leave 
Trifanovas, T. R. - 0 discurso do rei: tradução e poder

you? por "E qual é o seu papel em tudo isso?", em que o verbo estático leave, que denota passividade, é substituído pelo verbo de ação "ser".

Com tal escolha, há a possibilidade do suj eito tradutor vislumbrar que a personagem do terapeuta sabe que seu interlocutor, o duque de York, concebe uma ideia que não consegue admitir, a de querer ser rei e, mais ainda, a de que esteja tendo um papel determinante nas discussões para que isso realmente ocorra. Mas, não só o sujeito tradutor percebe o desejo contido da personagem do soberano, mas também o do terapeuta, que percebe o que o príncipe, conscientemente, é incapaz de dizer, ou seja, admitir sua participação velada na possível renúncia de seu irmão.

\section{RD 8}

LIONEL I'm just saying you could be King. You could do it!

Só estou dizendo que pode ser rei. Você consegue.

Da mesma forma que em RD 7, a tradução da fala, quase conseguinte, dos modais could por "pode", em lugar de "poderia", e, logo após, could por "consegue", e não por "poderia", remete a efeitos de sentido de que, ao retirar a condição subjuntiva, o tradutor faz emergir, no discurso, seu inconsciente, por meio de uma falha gramatical; não por não saber diferenciar um modal de outro, mas por já estar constituído pelo discurso que emerge no dizer das personagens. Em síntese, o terapeuta percebe o que 0 príncipe concebe secretamente e o tradutor percebe este desejo no interstício das falas que traduz. Este raciocínio tem respaldo na reação feroz do príncipe diante da insinuação do terapeuta de que o trono seja o lugar legítimo de seu paciente. Diante de tal invasão à sua pessoalidade, o príncipe humilha impiedosamente Lionel, não o terapeuta, mas o amigo que já se configurava como tal por já ter sido merecedor de confidências pessoais de sua família real.

Após esta discussão, o tratamento e a amizade são interrompidos por algum tempo. Lionel tenta pedir desculpas pelo seu atrevimento, mas George 
Trifanovas, T. R. - 0 discurso do rei: tradução e poder

não o recebe. Após a abdicação de seu irmão, Eduardo VIII, o príncipe se reconcilia com 0 terapeuta. O diálogo, a seguir, se passa na Abadia de Westminster, durante os preparativos para a coroação do príncipe como o Rei George VI. Contudo, nesta cena, apresenta-se mais um conflito entre ambos, pois o monarca confronta Lionel pela falta de diploma médico, conforme informações recebidas do Arcebispo de Canterbury, Cosmo Lang. O futuro rei, novamente, discute com Lionel.

\section{DIÁLOGO 4 Vídeo (tempo 1:24:05 - 1:28:32) Roteiro (páginas 71 - 74)}

LIONEL I can't believe I'm walking on Chaucer and Handel and Dickens.

Everything all right? Let's get cracking.

BERTIE I'm not here to rehearse, Doctor Logue.

True, you never called yourself 'Doctor'. I did that for you.

No diploma, no training, no qualifications. J ust a great deal of nerve.

LIONEL Ah, the star chamber inquisition, is it?

BERTIE You asked for trust and total equality.

LIONEL Bertie, I heard you at Wembley, I was there. I heard you.

My son Laurie said "Do you think you could help that poor man?"

I replied "If I had the chance".

BERTIE What, as a failed actor!?

LIONEL It's true, I'm not a doctor, and yes I acted a bit, recited in pubs and taught elocution in schools. When the Great War came, our boys were pouring back from the front, shell-shocked and unable to speak and somebody said, "Lionel, you're very good at all this speech stuff. Do you think you could possibly help these poor buggers". I did muscle therapy, exercise, relaxation, but I knew I had to go deeper. Those poor young blokes had cried out in fear, and no-one was listening to them. My job was to give them faith in their voice and let them know that a friend was listening. That must ring a few bells with you, Bertie.

BERTIE You give a very noble account of yourself.

LIONEL Make inquiries. It's all true. 
Trifanovas, T. R. - 0 discurso do rei: tradução e poder

BERTIE Inquiries have been made!

You have no idea who I have breathing down my neck. I vouched for you and you have no credentials.

LIONEL But lots of success! I can't show you a certificate - there was no training then. All I know I know by experience, and that war was some experience. My plaque says, 'L. Logue, Speech Defects'. No Dr., no letters after my name. Lock me in the Tower.

BERTIE I would if I could!

LIONEL On what charge?

BERTIE Fraud! With war looming, you've saddle this nation with a voiceless King.

Destroyed the happiness of my family... all for the sake of ensnaring a star patient you knew you couldn't possibly assist! It'll be like mad King George the Third, there'll be Mad King George the Stammerer, who let his people down so badly in their hour of need!

BERTIE What're you doing? Get up! You can't sit there!

LIONEL Why not? It's a chair.

BERTIE No, it's not, that is Saint Edward's Chair!

LIONEL People have carved their initials into it!

BERTIE That chair is the seat on which every King and Queen

LIONEL It's held in place by a large rock!

BERTIE That is the Stone of Scone, you are trivialising everything

LIONEL I don't care. I don't care how many Royal arses have sat in this chair

BERTIE Listen to me...!

LIONEL Listen to you?! By what right?

BERTIE Divine right, if you must! I'm your King!!!

LIONEL Noooo you're not! Told me so yourself.

Said you didn't want it. So why should I waste my time listening to you?

BERTIE Because I have a right to be heard!

LIONEL Heard as what?!

BERTIE A man! I HAVE A VOICE!!!

LIONEL Yes you do. You have such perseverance, Bertie, you're the bravest man I know.

And you'll make a bloody good king.

Vejamos, a seguir, como as falas selecionadas em negrito foram traduzidas, a fim de observarmos a produção de efeitos de sentido. 
Trifanovas, T. R. - O discurso do rei: tradução e poder

\section{RD 9}

BERTIE You have no idea who I have breathing down my neck. I vouched for you and you have no credentials.

Você não tem ideia da pressão que suporto. Dei-Ihe o meu aval e você não tem credenciais.

Considerando que a expressão idiomática breathing down my neck significa pressão exercida, por um superior, sobre alguém inferior, a escolha tradutória não permite efeitos de sentido similares. Coadunando com as análises anteriores, este recorte reafirma o raciocínio de que o sujeito tradutor resiste em posicionar o soberano inferiormente. Assim, prefere uma tradução mais condizente (Você não tem ideia da pressão que suporto) com a posição de poder e de autoridade da personagem, capaz de suportar pressão advinda da grande responsabilidade que carrega.

Da mesma maneira, ao preferir traduzir I vouched for you por "Dei-Ihe o meu aval", o suj eito tradutor parece contrariar sua empreitada de assegurar a posição de poder do soberano - mesmo em se tratando de um monarca infantilizado e inseguro -, pois "dar aval" remete a um ato corriqueiro, do cotidiano de homens comuns e não de homens nobres. Já voucher for you pressupõe a necessidade de um estar em posição superior a de um outro, neste caso, o soberano, em condições de proteger o homem comum, lançando mão de sua posição de poder. Esta escolha tradutória sugere um possível deslize de sentido do tradutor, cuja posição sujeito já se encontra multifacetada pelas condições de produção em relação ao enredo, à tradução, aos personagens e à atuação dos atores. Neste enunciado, George se apresenta consciente de seu poder, declarando que Lionel estava sob sua proteção. 
Trifanovas, T. R. - 0 discurso do rei: tradução e poder

RD 10

BERTIE With war looming, you've saddle this nation with a voiceless King.

Com guerra iminente, você selou esta nação sem a voz do rei.

Contudo, logo a seguir, o sujeito tradutor retoma a tentativa de colocar a personagem do príncipe em posição de superioridade, responsabilizando o terapeuta por agir sem a autorização do rei (sem a voz do rei), o que contradiz a fala original do monarca que se reconhece inferior por não ter voz (a voiceless king). Assim, o sujeito tradutor tenta novamente amenizar a figura de um monarca sem poder e sem autoridade.

RD 11

LIONEL I don't care. I don't care how many Royal arses have sat in this chair.

Não me importa quantos traseiros reais sentaram-se aqui.

Por fim, ao traduzir a palavra arses por "traseiros" observa-se 0 conceito doublebinding, da teoria de Derrida, que reflete o dilema do tradutor em escolher por duas possibilidades cujos sentidos são distintos ou, por vezes, contraditórios, por exemplo, pharmacón pode ser traduzido por remédio ou por veneno. Neste recorte, o sujeito tradutor parece incapaz de conceber que qualquer referência a ilustres soberanos possa estar aliada ao adjetivo "jumentos" e, por isso, prefere o substantivo "traseiros". Ressaltamos que tanto as palavras ass, asses, arse ou arses podem ser traduzidas como "traseiro(s)", "asno(s)" ou "jumento(s)". 
Trifanovas, T. R. - O discurso do rei: tradução e poder

\section{Conclusão}

A partir do dispositivo analítico, pudemos confirmar nossa hipótese, observando que o sujeito tradutor faz emergir, esporadicamente, em seu discurso, nuances do imaginário coletivo. Vimos, também, os desafios da tradução no que se refere às escolhas lexicais. Considerando a "imperfeição" das línguas, haverá sempre a falta de algo que será encontrado em outra língua, pois mesmo diferentes, as línguas se misturam umas as outras. Contudo, a junção de todas as línguas é impossível e a completude definitiva nunca será possível - mito da Torre de Babel: a língua pura. Freud, ao longo de sua obra, ensina que quando se consegue interpretar algo que veio à tona é tradução e não interpretação.

Finalizamos, ressaltando que não objetivávamos uma verificação da qualidade da tradução e, sim, a reflexão de como o embate das relações de poder ocorreriam durante 0 ato tradutório. Há que se pensar que o texto está sempre à espera do tradutor, pois o ato tradutório faz emergir aspectos do texto que ficaram imperceptíveis na língua de origem; só a tradução traz o acontecimento linguístico que não se reduz a simples transmissão de um texto de uma língua para a outra.

\section{Referências bibliográficas}

Authier-ReVUZ, J . Palavras Incertas: As Não-Coincidências do Dizer. Campinas, SP: Editora da Unicamp, 1998.

CoracinI, M.J.R.F. Análise de Discurso: em Busca de uma Metodologia. D.E.L.T.A. São Paulo, Associação Brasileira de Lingüística, 1991. vol. 7, n. 1, p. 333-355.

CoRACINI, M.J.R.F. A Celebração do Outro: Arquivo. Memória e Identidade: Línguas (Materna e Estrangeira), Plurilingüismo e Tradução. Campinas, SP: Mercado de Letras, 2007. 
Trifanovas, T. R. - 0 discurso do rei: tradução e poder

FoucAult, M. A Arqueologia do Saber. 7ạ ed, 1a reimpressão.Tradução de Luiz F. B. Neves. Rio de Janeiro, RJ: Editora Forense Universitária, 2005 [1969].

Foucault, M. História da Sexualidade I: A Vontade de Saber. 5a ed. Rio de J aneiro, RJ :Edições Graal, 1984 [1976].

ORLANDI, E.P. Análise de Discurso - Princípios e Procedimentos. 3a ed. Campinas, SP: Pontes, 2001. 